\title{
The Effects of Process Parameters on Evolutions of Thermodynamics and Microstructures for Composite Extrusion of Magnesium Alloy
}

\author{
H.-J. Hu ${ }^{1,2}$ \\ ${ }^{1}$ Key Laboratory of Manufacture and Test Techniques for Automobile Parts, Chongqing University of Technology, \\ Ministry of Education, Chongqing 400050, China \\ ${ }^{2}$ College of Material Science and Engineering, Chongqing University of Technology, Chongqing 400050, China
}

Correspondence should be addressed to H.-J. Hu; 48516686@qq.com

Received 11 May 2013; Revised 5 September 2013; Accepted 9 September 2013

Academic Editor: Richard Hennig

Copyright (C) 2013 H.-J. Hu. This is an open access article distributed under the Creative Commons Attribution License, which permits unrestricted use, distribution, and reproduction in any medium, provided the original work is properly cited.

\begin{abstract}
To research the effects of process parameters on evolutions of extrusion force and temperature rise and microstructures for composite extrusion of magnesium alloy which includes initial extrusion and shearing process subsequently and is shortened for "ES" in this paper, the ES extrusion process has been researched by using finite element modeling (FEM) technology. The rules of temperature rise and the extrusion force varying with process parameters have been developed. The thermal-mechanical coupling finite element models including the geometric and FEM models and solution conditions were applied to calculate the effective strain and temperature and extrusion force during ES extrusion. The maximum temperature rises in the billets do not increase with billet temperature rising. The temperature of rod surface increased continuously with development of ES extrusion. The evolutions of extrusion load curve and effective stress and temperature can be divided into three stages obviously. Extrusion experiments have been constructed to validate the FEM models with different process conditions. The simulation results and microstructure observation showed that ES process can introduce compressive and accumulated shear strain into the magnesium alloy. The ES extrusion would cause severe plastic deformation and improve the dynamic recrystallization during ES extrusion. The microstructures show that ES is an efficient and inexpensive grain refinement method for magnesium alloys.
\end{abstract}

\section{Introduction}

The specific strength of magnesium alloys is high, and use of magnesium parts would cause weight saving of around $30 \%$ and $70 \%$ compared to aluminum and steel, respectively. Currently, market for magnesium alloys is fast expanding from automobiles to electronic applications. Structural applications normally require energy absorption materials with reasonable elongation, high yield strength, and high impact energy. In recent years, bulk nanostructure materials processed by severe plastic deformation (SPD) such as equal channel angular extrusion (ECAE) have attracted the growing interest of specialists in materials science. The important phenomena observed in of ECAE process for magnesium alloys are the DRX (dynamic recrystallization) and DRV (dynamic recovery), which could improve the workability of the material at elevated temperatures. M. Furui et al. have researched the influences of preliminary extrusion conditions on the superplastic properties of a magnesium alloy twophase $\mathrm{Mg}-8 \% \mathrm{Li}$ processed by ECAP in three different conditions including cast condition, cast + extrude condition, and cast + extrude + ECAP condition [1]. It is shown that it is advantageous to use a die with a channel angle of $135^{\circ}$ because it permits pressing at room temperature where grain growth is limited. Ding et al. used three processing routes of equal channel angular extrusion (ECAE) to process $\mathrm{Mg}$ alloy [2]. Tensile strengths, grain sizes, and textures of these processed billets were measured to investigate the effect of processing route on the mechanical properties and the strengthening mechanism. Route A is the only route that can increase the strength by ECAE. A multiple-temperature ECAE procedure has been developed to produce high-strength $\mathrm{Mg}$ alloy, which 
is a combined result of submicron grain structure and texture strengthening.

But the ECAP process is only used in the laboratory and preparation for nanocrystalline material, there exists an unbridgeable gap between the experiments and industrial applications. The productivity of ECAP in industrial manufacturing is very low; ECAP usually involves many steps and is not easily applied from the laboratory to an industry, for it is not a continuous process, but the dimension of extruded rods is the same as that of initial billets. Although ECAP technology has been invented as early as 1980s, the process did not progress as much as one would desire and is still confined to the laboratory scale experiments. Figueiredo et al. used a new processing procedure to extrude a cast $\mathrm{Mg}-9 \%$ $\mathrm{Al}$ alloy involving the sequential application of extrusion and equal channel angular pressing. Experiments showed that the $\mathrm{Mg}-9 \% \mathrm{Al}$ alloy has an initial grain size of $\sim 50 \mu \mathrm{m}$ after casting but this was reduced to $\sim 12 \mu \mathrm{m}$ after extrusion and it was further reduced to $\sim 0.7 \mu \mathrm{m}$ when the extruded alloy was subjected to ECAP for 2 passes at $473 \mathrm{~K}$ [3]. Although the cast alloy exhibits extremely limited ductility and the extruded alloy was only moderately ductile, the research results demonstrated that processing by EX-ECAP could produce excellent superplastic ductility. But EX-ECAP usually includes more than 2 steps, and the material endures intricate diversification of forming environments including process temperature and may be oxidized.

The paper written by Orlov et al. demonstrated the feasibility of severe plastic deformation (SPD) techniques which combine conventional extrusion and equal channel angular pressing in a single process [4]. The processed material exhibited an excellent balance of strength and tensile ductility. It had yield strength of $310 \mathrm{MPa}$ and the ultimate tensile strength of $351 \mathrm{MPa}$. The total elongation of $17.1 \%$ was about 2.5 times and the reduction in area of $42.5 \%$ was more than 10 times larger than the corresponding values in the asreceived condition. Composite extrusion method for magnesium alloy has been presented which combines the traditional extrusion and the severe plastic deformation ECAP (equal channel anger pressing); that is to say, extrusion and shearing (one or more than one) are combined (referred to as ES in this paper). The ES may improve the industrialization preparation and processing of magnesium alloy rods (profiles). The ES extrusion is also continuous extrusion process. In order to secure a process with a sustainably high level of accuracy, tools must be precisely adjusted and utilized. In addition, process parameters must be carefully checked in order to ensure a high level of quality in production.

It is accepted that the magnesium material properties are closely correlated to the microstructures, for the influence of the process conditions on the evolution of structure is very important from Chang et al. Process conditions include some extrusion parameters such as the extrusion speed, the initial temperature, and friction and heat transfer of the billet, container, and die and have great effects on the grains structure [5].

To illustrate the potential industrial application of the ES extrusion, ES die used in the horizontal extruder has been designed and manufactured, and the experiments of ES

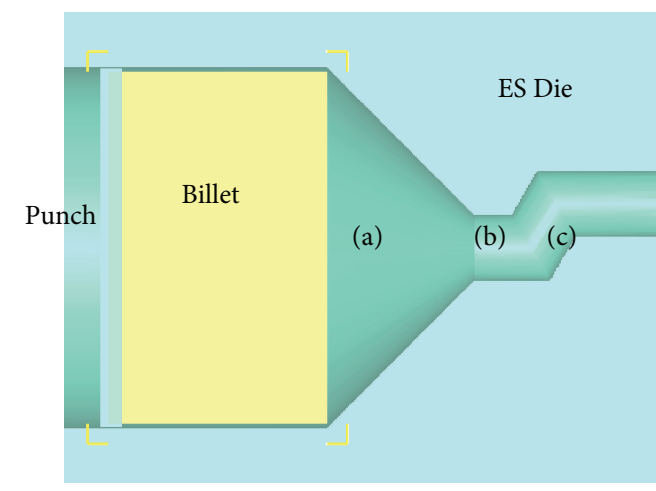

Figure 1: ES die and billet (a) direction extrusion stage, (b) first shearing, and (c) second shearing.

extrusion have been done. Controlling the submicrostructures distribution in the final products is a challenging and demanding task for the ES extrusion industry. The aims of the present study are to reveal the microstructures' evolution and clarify the grain refinement mechanism for AZ31 magnesium alloy during ES process. The present studies employ DEFORM-3D finite element software to simulate the extrusion forces, temperature distributions, and strain evolution during ES extrusion. The microstructures of AZ31 $\mathrm{Mg}$ alloy sampled from ES extruded rods have been observed. Deformed microstructure evolutions of the ES process for AZ31 magnesium alloy have been studied in order to analyze the deformation mechanisms.

\section{Simulation and Experimental Conditions of ES Process}

2.1. Simulation Conditions. The longitudinal section schematic diagram of ES extrusion is schematically shown in Figure 1. The die includes direction extrusion with extrusion ratio of 32.1 and two steps of equal channel angular processing (ECAP) with $120^{\circ}$ corner angle. Figure 1 shows each stage that ES extrusion process is divided into: (a) direction extrusion stage, (b) first shearing, and (c) second shearing. The model has been established symmetrically. A larger amount of shear deformation by ES extrusion can be introduced than that by direct extrusion with the same extrusion ratio.

The billets and the die in experiment have identical geometrical parameters and material with those in simulations. The AZ31 magnesium materials should be preheated; the ram and the lubricated die in the furnace have been heated for 2 hours before the actual extrusion process. The ES extrusion is then employed to extrude the magnesium alloy rods. Real extrusion experiments have been carried out by employing a 500-ton press with a resistance-heated container and a heater. The die material, die dimensions, billet dimensions, and extrusion conditions are all the same as those used in numerical simulation as described in Table 2. The billet has been heated in an external furnace up to $420^{\circ} \mathrm{C}$ and transported into the container at a preset temperature of $400^{\circ} \mathrm{C}$ to avoid too much heat dissipation, and then extrusion started immediately. Ram speed is $2 \mathrm{~mm} / \mathrm{s}$ during experimental verification. The physical property of AZ31B is 
TABLE 1: Physical properties of the AZ31 workpiece.

\begin{tabular}{|c|c|}
\hline Property & AZ31 \\
\hline 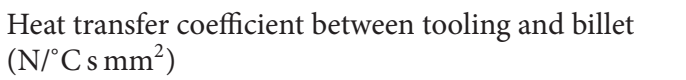 & 11 \\
\hline 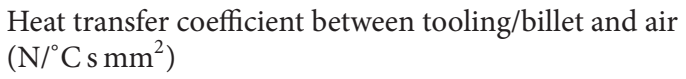 & 0.02 \\
\hline Poisson's ratio & 0.35 \\
\hline Coefficient of linear expansion & $26.8 E-6$ \\
\hline Density $\left(\mathrm{Kg} \cdot \mathrm{m}^{-3}\right)$ & 1780 \\
\hline Poison's ratio & 0.35 \\
\hline Young's modulus (Map) & 45000 \\
\hline Emissivity & 0.12 \\
\hline
\end{tabular}

TABLE 2: Simulation and experimental parameters.

\begin{tabular}{lc}
\hline Billet length $(\mathrm{mm})$ & 100 \\
Billet diameter $(\mathrm{mm})$ & 80 \\
Insider diameter of container $(\mathrm{mm})$ & 85 \\
Outside diameter of container $(\mathrm{mm})$ & 110 \\
Die bearing length $(\mathrm{mm})$ & 5 \\
Extrusion ratio & 32.1 \\
Initial billet temperature $\left({ }^{\circ} \mathrm{C}\right)$ & $380,400,420$ \\
Initial tooling temperature $\left({ }^{\circ} \mathrm{C}\right)$ & $380,400,420$ \\
Temperature range for flow stress measurement $\left({ }^{\circ} \mathrm{C}\right)$ & $400-450$ \\
Ram speed (mm/s) & $1,2,5,10$ \\
Friction factor of the container-billet interface & $0.1,0.4$ \\
Friction factor between the billet and die & $0.1,0.4$ \\
Total number of elements & 20000 \\
Minimum size of element $(\mathrm{mm})$ & 1 \\
Mesh density type & Relative \\
Relative interference depth & 0.7 \\
\hline
\end{tabular}

given in Table 1. Simulation and experimental parameters are shown in Table 2.

Axial compression testing for hot workability analysis was carried out using a Gleeble 1500 D machine. Graphite foils were placed between the billet and die for lubrication. At a constant strain rate ranging from 0.01 to $10 \mathrm{~s}^{-1}$ and at an initial temperature between 250 and $500^{\circ} \mathrm{C}$, the specimen was resistance-heated through a thermocouple sending feedback signals to control the AC current. The flow stress curves measured in these tests were corrected and a set of flow stress-strain curves are shown in Figure 2 as examples with strain rate of $0.1 \mathrm{~s}^{-1}$ and the different preset temperatures $250^{\circ} \mathrm{C}, 300^{\circ} \mathrm{C}, 350^{\circ} \mathrm{C}$, and $400^{\circ} \mathrm{C}$. The data were input into the material property module of the DEFORM-3D software.

2.2. Experimental Setup and Tests. The billets have been heated in an electric furnace and soaked for one hour, and the container was heated to working temperature by resistanceheated device. The billets have been heated $20^{\circ} \mathrm{C}$ more to decrease the heat loss during handling from the furnace to the container. Billet preheated temperatures of 420 have been

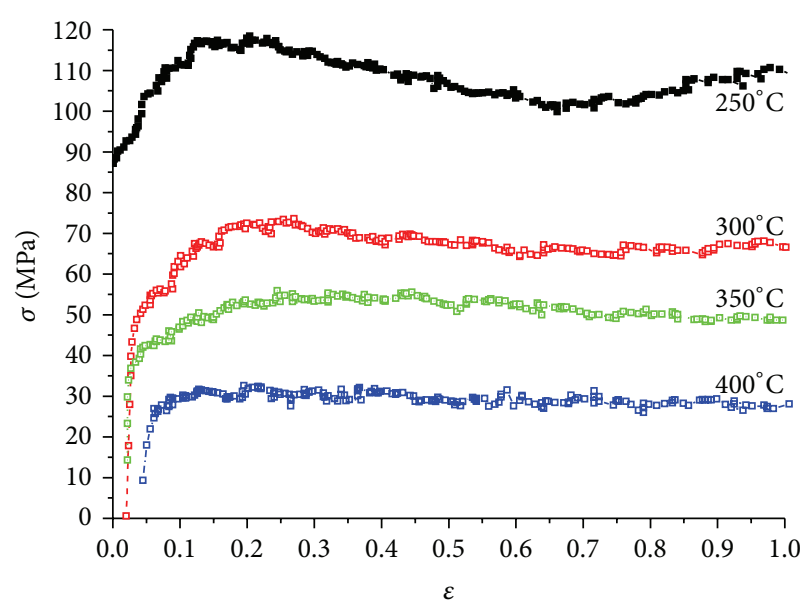

FIGURE 2: True stress/true strain curves obtained from the compression tests with strain rate $0.1 \mathrm{~s}^{-1}$ and the different preset temperatures $250^{\circ} \mathrm{C}, 300^{\circ} \mathrm{C}, 350^{\circ} \mathrm{C}$, and $400^{\circ} \mathrm{C}$.

used. The initial container and die temperature as well as the ram speed were $400^{\circ} \mathrm{C}$ and $2 \mathrm{~mm} / \mathrm{s}$, respectively. To preserve the achieved microstructure of the rod after extrusion, the samples have been water quenched for a handling time of approximately $3 \mathrm{~s}$. Subsequently, some specimens have been taken from different positions in the rod, and all the samples were taken from the center of rod. The polished surface has been etched using either a solution of $1 \mathrm{vol} \% \mathrm{HNO}_{3}, 24 \mathrm{vol} \%$ $\mathrm{C}_{2} \mathrm{H}_{6} \mathrm{O}_{2}$, and 75 vol\% $\mathrm{H}_{2} \mathrm{O}$ or of $10 \mathrm{~mL}$ acetic acid, $4.2 \mathrm{~g}$ picric acid, $10 \mathrm{~mL} \mathrm{H}_{2} \mathrm{O}$, or $70 \mathrm{~mL}$ ethanol. Microstructure observations have been carried out using PME OLYMPUS TOKYO-type optical microscope (OM).

\section{Research Results and Discussion}

3.1. Temperature Evolution. During the ES extrusion process, temperatures of the die exit are affected by many parameters including initial billet temperatures, ES extrusion speeds, extrusion ratios, and friction factors between the billet and die. The heat generated by the ES extrusion and friction factors significantly increases the temperatures of the rod and microstructures and mechanical properties. The temperature rise also influences the surface quality of the extruded rods, which is of prime importance in many industrial extrusion processes. Because ES extrusion is a nonlinear process involving high inhomogeneous deformation and high strain rate, it is difficult to predict the temperature of billet analytically. If we neglect the temperature gradients and the deformation material is considered as a thin plate, the average instantaneous temperature of the deformed material at the interface is given by the following [6]:

$$
T=T_{1}+\left(T_{0}-T_{1}\right) \exp \left(\frac{-h t}{\rho c \delta}\right),
$$

where $T_{0}$ is initial temperature for the workpiece, $T_{1}$ is temperature for the die, $h$ is heat transfer coefficient between the material and the dies, and $\delta$ is material thickness between the dies. If the temperature increase due to deformation and 


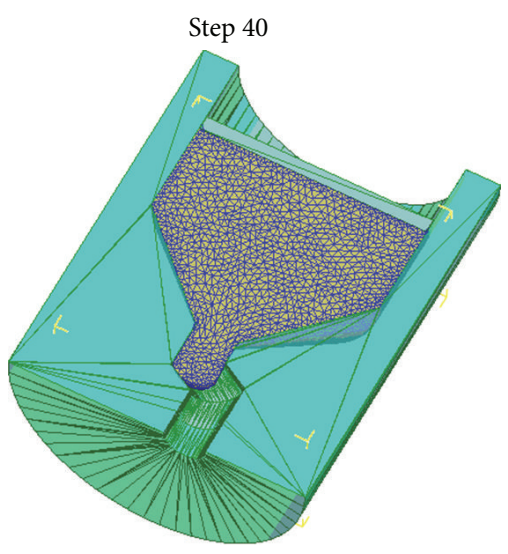

(a)

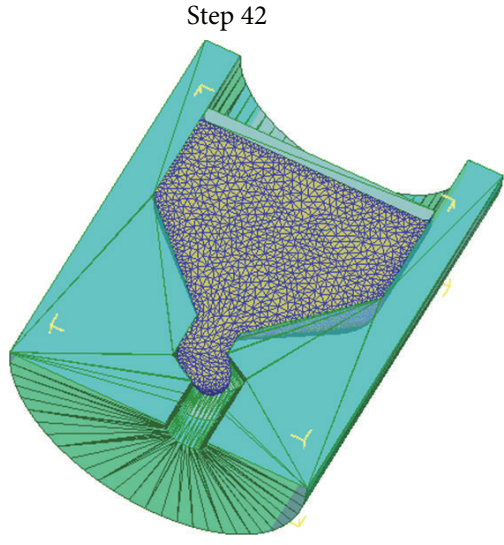

(b)

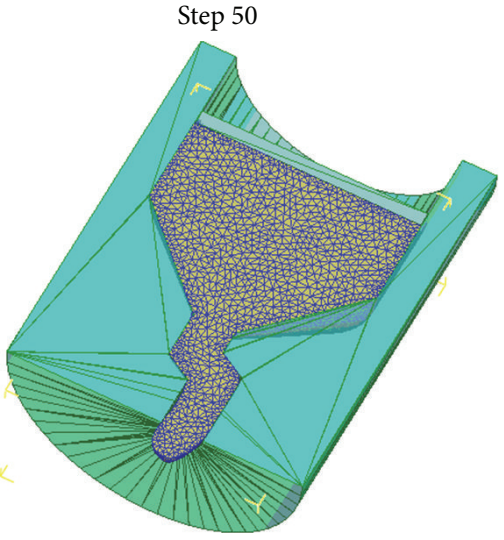

(c)

FIGURE 3: AZ31 material flow for ES process, extrusion stages of ES die: (a) direction extrusion stage, (b) first shearing, and (c) second shearing.

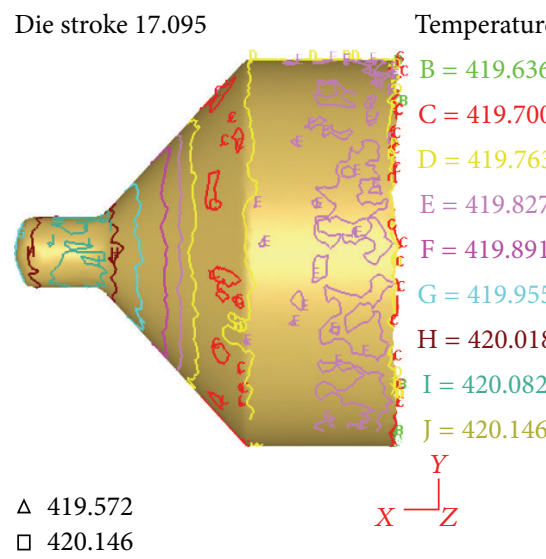

(a)

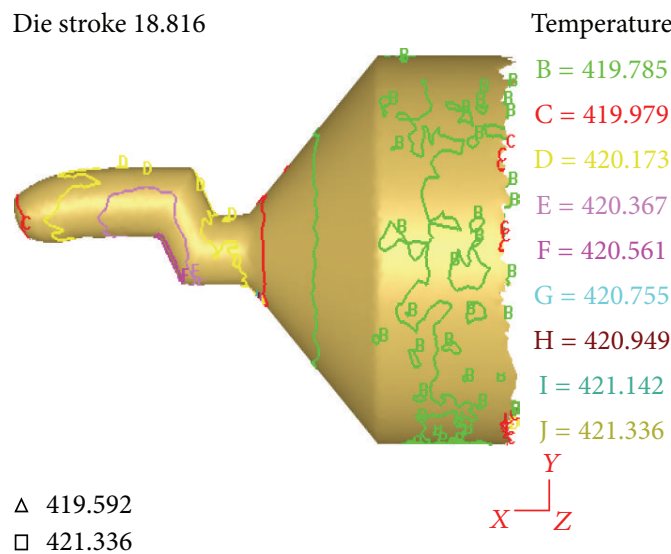

(b)

FIGURE 4: Temperature contours in the billet extruded at a ram speed of $2 \mathrm{~mm} / \mathrm{s}$ and at the displacements of (a) $17.095 \mathrm{~mm}$ and (b) $18.816 \mathrm{~mm}$.

friction is included, the final average material temperature $T_{m}$ at a time $t$ is as follows [7]:

$$
T_{m}=T_{d}+T_{f}+T
$$

where $T_{d}$ is temperature for frictionless deformation process and $T_{f}$ is temperature increase due to friction. According to energy conservation principle, mathematical models of temperature rise as (3) have been established in the ES deformation zone [8]:

$$
\Delta T=\frac{(0.29 f+0.9 \varepsilon) \sigma_{s}}{C \rho+h},
$$

where $\varepsilon$ is the effective strain.

ES die extrusion is divided into four steps according to material flow which is shown in Figure 3. Firstly, the billet is compressed and initial billet is compressed into the die entrance. Secondly, the extrude material is formed and the final rod diameter was obtained during direction extrusion stage. Thirdly, the formed rod is sheared by the first turn angle in first shearing step and the rod is sheared at the second turn angle.

Figure 4 shows the temperature contour lines in the extruded rods at a ram speed of $2 \mathrm{~mm} / \mathrm{s}$ and the displacements are $17.095 \mathrm{~mm}$ and $18.816 \mathrm{~mm}$ corresponding to direction extrusion stage and the first shearing stage of the process, respectively. Comparison of the temperature distributions at these two positions demonstrates the thermal characteristics within the billet and the heat transfer from the deformation zone in front of the die towards the outsides of the billet. Figure 4(a) shows that the temperatures of the billet at the beginning of the process are various and below the initial billet temperature $420^{\circ} \mathrm{C}$ if heat is produced in the extrusion zone and temperature gradients are formed. Obviously, this is due to heat loss to the ES die with its initial temperature of $400^{\circ} \mathrm{C}$ which is lower than the initial temperature of billets. The heat flows along the radial direction and the axial direction in the billet. It is apparent that heat has already been conducted toward the periphery and the rear end of the billet. Temperatures of half billet are below the initial billet temperature in Figure 4(b); the reasons are the results of time 


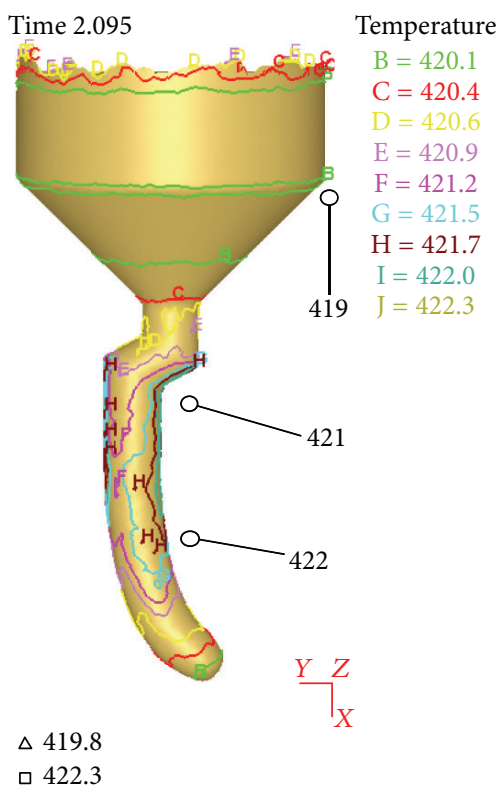

Figure 5: Temperature distribution in the billet during the extrusion process at the steady state regime (initial billet temperature of $420^{\circ} \mathrm{C}$, ram speed of $2 \mathrm{~mm} / \mathrm{s}$ ).

available for continuous heat loss to the ES die and through the die of the ambient surround.

The temperature evolution in the billet (initial temperature: $420^{\circ} \mathrm{C}$ ) as the extrusion proceeds steady state is shown in Figure 5. It is clear that the temperature of rod surface increases continuously with development of ES extrusion. The factors to increase the temperature during the ES process are (1) heat transfer from die and punch, (2) friction between the rod material and die, and (3) plastic deformation during the ES forming process.

The maximum temperatures varying with extrusion time and billet preheated temperatures at the exit of extrusion die are compared and the results are shown in Figure 6. It is noticed that the increases in maximum temperature predicted by the finite element simulations are not significant, but it is seen that the finite element simulation results vary with preheated temperatures. It is uniquely found that the increase in the maximum temperature is not significantly various. The reason for the lower temperature increments at higher forming temperatures is mainly due to lower temperature gradient between the die and billets. Since the temperature rise depends on the heat generated within the deformation zone. Heat generation depends on the internal power of deformation and frictional power. Variations of different parameters affect the power constituents which affect the heat generation within the deformation zone. Bigger surface temperatures may cause surface cracks and tears, for the tensile strength of the AZ31 rod is decreased.

\subsection{Load-Stroke Curves with Different Friction Conditions.} ES extrusion is a hot working process; the magnesium alloy may be heated over the recrystallization temperature. ES extrusions are done on horizontal hydraulic presses which range from 100 to 11,000 metric tons. As a result of $\mathrm{FE}$

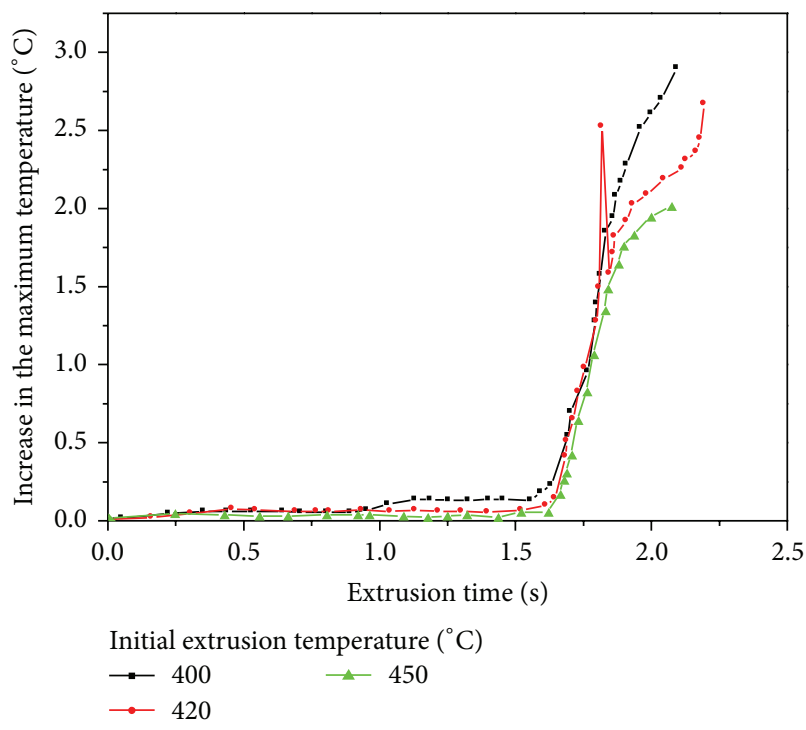

FIgURE 6: Maximum temperatures for various initial extrusion temperatures during ES extrusion through ES die and at ram speeds of $2 \mathrm{~mm} / \mathrm{s}$ with preheated temperature $400-420^{\circ} \mathrm{C}$.

analysis, Figure 7 shows load-stroke curves for ES extrusion with different shear friction coefficients. The effects of friction coefficients on the extrusion forces have been obtained from the finite element simulations with various friction factors. In theory, friction energy of ES extrusion die is higher than that of ordinary extrusion die. In the case of ES extrusion die, because ES extrusion die has bigger plastic deformation zone than that of ordinary extrusion die, deformation energy of ES extrusion is bigger.

It is found that the effects of friction coefficients on the direct extrusion are not significant before extrusion time is $1.6 \mathrm{~s}$ as ES extrusion reaches steady state after $1.6 \mathrm{~s}$. The extrusion forces increase more rapidly; maximum loads are 250 tons and 200 tons for friction coefficients 0.4 and 0.1, respectively. From these results, maximum loads of ES die increase as the friction coefficient rises. For larger friction coefficient, the increasing in the extrusion force can be clearly seen. It is indicated that extrusion force is very sensitive to variations of the friction coefficient, so it is necessary to carry lubrication into ES dies.

3.3. Extrusion Force Varying with Different Extrusion Speeds. Figure 8 shows the extrusion force/extrusion time diagrams obtained at various extrusion speeds, which shows that the peak extrusion force increases with extrusion speed. It is observed that initially the load increases slowly because of the clearance between billet-container interfaces and the billets being first filled during the ES extrusion deformation gradually. Then, the extrusion force increases rapidly till the values are stable. The contact area of friction between billet and container wall becomes smaller, and the frictional forces become smaller correspondingly. With higher ram speeds, the breakthrough pressure is higher due to strainrate hardening, and over the pressure peak, the slope of pressure decrease is steeper. The force decrease is attributed 


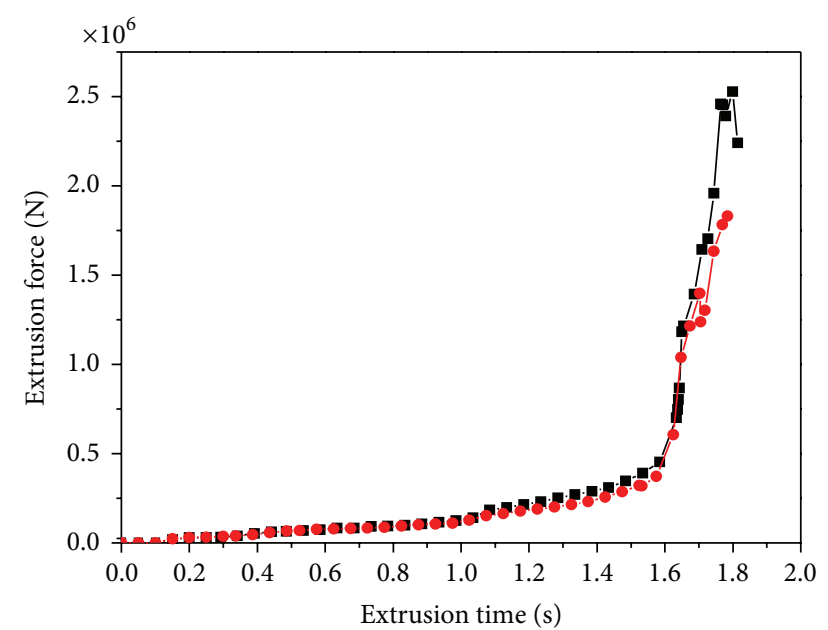

Frictional coefficient with the same other conditions

$\rightarrow-0.4$

$\longrightarrow 0.1$

FIGURE 7: ES extrusion loads for various friction factors.

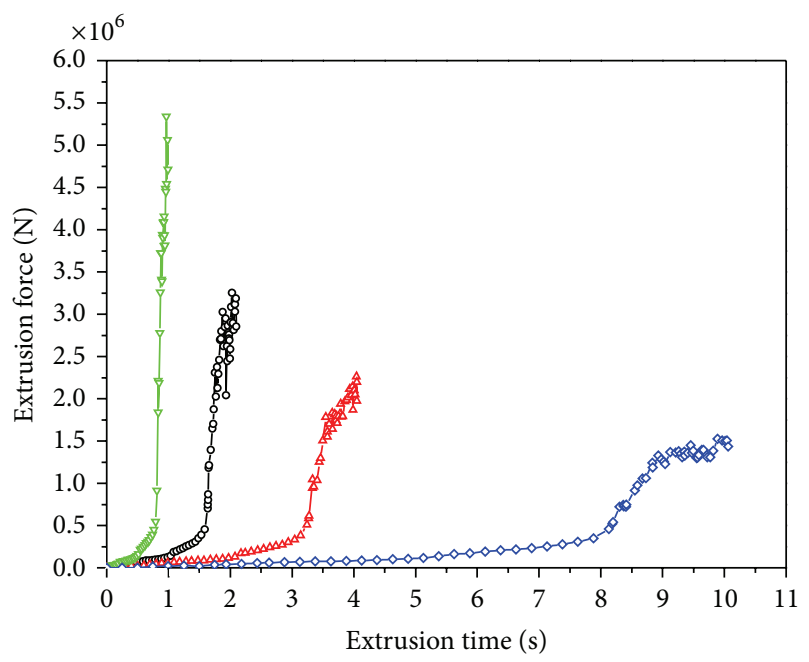

Extrusion velocity $(\mathrm{mm} / \mathrm{s})$ with the same other conditions $\begin{array}{ll}\multimap-1 & \rightarrow 5 \\ \neg-2 & \rightarrow-10\end{array}$

FIGURE 8: Extrusion force/extrusion time diagrams obtained at various extrusion speeds.

to a shortening billet and thus a decreasing friction force between the billet-container interfaces by the classic theory of metal extrusion.

3.4. Microstructures Observation. After the extrusion process, the extruded rods have been quenched and investigated metallographically. Figure 9(a) depicts the microstructure of the longitudinal section in the rod after ES extrusion is complete. After quenching, samples of extrusion temperatures show fully developed equiaxed small grains with large angle grain boundaries, which indicate the appearance of geometric dynamic recrystallization. Microstructure evolution has been observed according to the change in strain distribution and

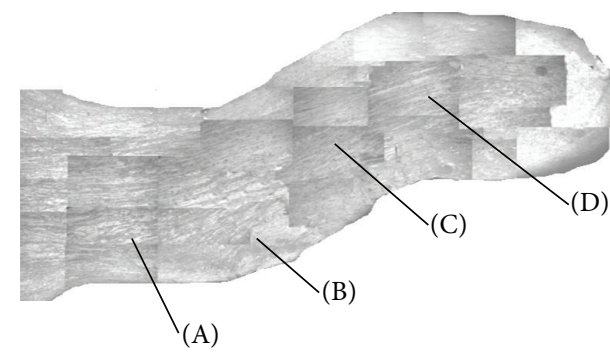

(a)

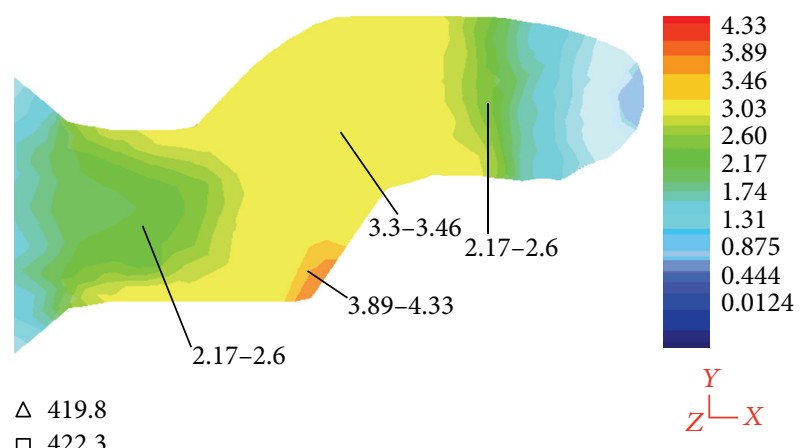

(b)

FIGURE 9: Final microstructure of the extrudate at $420^{\circ} \mathrm{C}$ and strain distribution diagram obtained from FEA.

strain values. In region " $\mathrm{A}$ " in Figure 9(b), the strains are about 2.17-2.6; the grain structure and size are rather similar to the state prior to deformation, for the grains are deformed very little to a large extent. There are very small recrystallized grains in the extruded rods. The small refined grains can be attributed to partial dynamic recrystallization occurring during the direct extrusion period. As strain values increase to values above 4 , more refined grains can be observed in region "B" (strain values about 3.89-4.33). At the heavily worked region such as region " $\mathrm{B}$," the microstructures could be fully recrystallised. In region "C," the strain values are about $0.9-1.4$. It is noted that the final microstructures of the part are inhomogeneous, and there exists larger grain size or elongated grains, and typical fibrous structure with very long grains is aligned in the extrusion direction. In region " $D$," the strain values are about $1.5-1.7$, the microstructures are entirely refined and equiaxed grains, and full recrystallisation has taken place. Such observation of reduced grain size with increased strain may be attributed to dynamic recrystallization affected by effective strains, and higher strains can provide more nuclei per unit volume.

The principle of ES process is to introduce compressive and accumulated shear strains into the magnesium alloy. The character of ES process is that the sample is subjected to two shear deformations. The accumulative strains of ES extrusion can be expressed as (4) which include accumulative strain of direct extrusion and two continuous ECAP steps [9]:

$\varepsilon=\ln \lambda+2^{*}\left[\frac{2 \cot ((\phi / 2)+(\psi / 2))+\psi \csc ((\phi / 2)+(\psi / 2))}{\sqrt{3}}\right]$, 


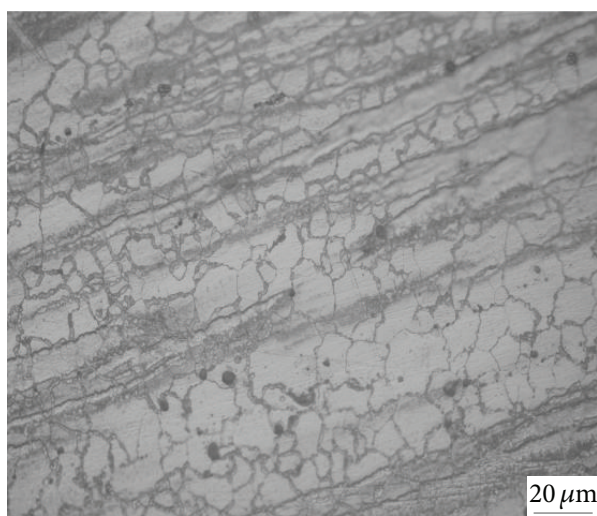

(a)

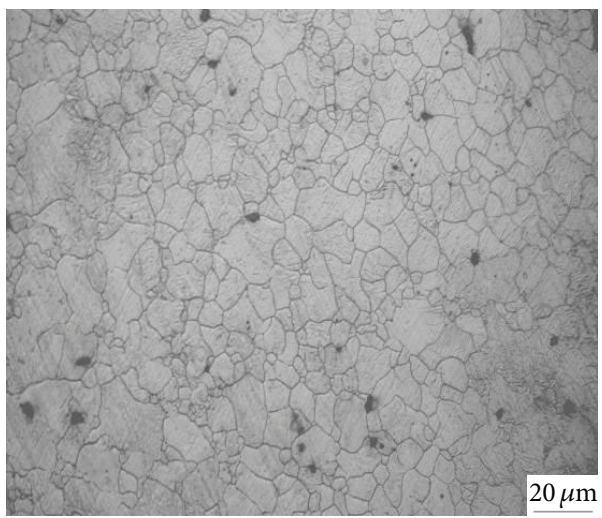

(c)

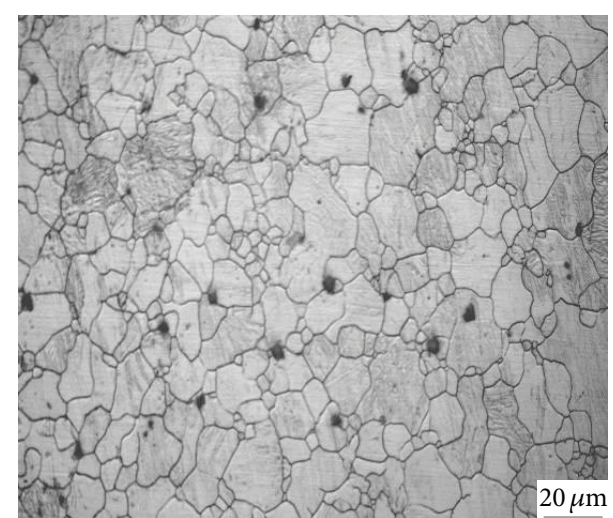

(b)

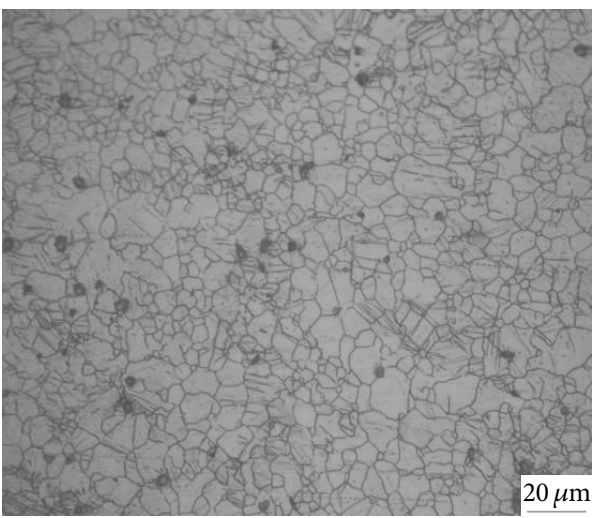

(d)

Figure 10: Microstructures of AZ31 magnesium alloy in different parts of ES die (×400): (a) region "A", (b) region "B", (c) region “C”, and (d) region " $D$ ".

where $\varepsilon$ is the accumulative strain, $\lambda$ is the extrusion ratio, $\Phi$ is the inner corner angle, and $\Psi$ is the outer corner angle.

Figure 10 shows the microstructures in four parts within rod formed by ES process. The microstructures appear as strips along the extrusion direction shown in Figure 10(a) in the extruded reducing zone. This indicates that the deformation degree is very small. The uniform deformation took place in the grains mainly and improved the formation of rodlike microstructures in Figure 10(b) while recrystallization occurred in a small number of grains. As the deformation continues, the width of the rod-like microstructures becomes narrow; a number of lamellar-structure twin grains appear in the grains shown in Figure 10(c), where partial crystallization has taken place in those positions. Rod-like and lamellar microstructures in the first shear zone began to reduce for the large shear strain caused by shear deformation in this zone, and the deformation grains were turned into recrystallization grains. In the secondary shear zone shown in Figure 10(d), dynamic recrystallization occurred sufficiently for bigger cumulative shearing strains, but there was still a small amount of fine grain bars in the center of the rod. Using ES extrusion process, the average grain size can be changed from $250 \mu \mathrm{m}$ to $10 \mu \mathrm{m}$. The microstructures were not only clearly refined but also relatively uniform. This was because the ES process included two simple shear extrusion processes more than an ordinary extrusion so that the deformation degree of central part of rods increased and the part recrystallization occurred. Therefore, the microstructures became smaller and more homogeneous.

The relationship between the average recrystallization grain size $(d)$ and the Zener-Hollomon parameter $(Z)$ during dynamic recrystallization is given by (5) and (6) [10]. The Zener-Hollomon parameter is used to help describe hightemperature creep strain of a material such as steel. The Zener-Hollomon parameter is also known as the temperature-compensated strain rate:

$$
\begin{gathered}
Z=\dot{\varepsilon} \exp \left(\frac{Q}{R T}\right), \\
-\ln \mathrm{d}=A+B \ln Z,
\end{gathered}
$$

where $\mathcal{\varepsilon}$ is the strain rate, $Q$ is the activation energy, $R$ is the gas constant, $T$ is the temperature, and $A$ and $B$ are constants.

Dynamic recrystallization (DRX) is one of the interesting mechanisms of microstructure evolution. Grain refinement could be attributed to continuous dynamic recrystallization which involves a progressive increase in grain boundary disorientation and changes of low angle boundaries into high angle boundaries. The Zener-Hollomon parameter $(Z)$ of first direct extrusion is equal to $Z_{1}, v_{1}$ is the extrusion speed, $\lambda$ is 
the extrusion ratio, and $R_{1}$ is the billet radius. The parameters were substituted into (7); hence, (8) is obtained:

$$
Z_{1}=\frac{3 v_{1}}{R_{1}} \ln \lambda \exp \left(\frac{Q}{R T}\right) .
$$

And the $Z$ parameters of the first and the second shearings are $Z_{2}, Z_{3}$, respectively:

$$
\begin{aligned}
Z_{2}=Z_{3}=\left[\frac{2 \cot ((\phi / 2)+(\psi / 2))+\psi \csc ((\phi / 2)+(\psi / 2))}{\sqrt{6}}\right] \\
\times \frac{\sqrt{v_{2}}}{\psi R_{2}} \exp \left(\frac{Q}{R T}\right),
\end{aligned}
$$

where inner corner angle is $(\Phi)$, outer corner angle is $(\psi), V_{1}$ is the speed of extruded rods, and $R_{2}$ is radius of extruded rod.

Based on the present ES processing with extrusion temperature of $420^{\circ} \mathrm{C}$, from (5) to (8), it can be found that the accumulative strain increases with the extrusion advancing, so the grains will be refined consequently. It is clear that there is three-phase recrystallization during ES process. It can be found that the average sizes of grains for DRX were coarsened with the preheated temperature increasing.

\section{Conclusions}

Three-dimensional finite element DEFORM software has been utilized to research the rules of temperature and the extrusion force varying with process parameters. Some ES extrusion experiments and tests have been done to research the plastic deformation behaviors of magnesium billet during ES extrusion through an ES die. The results have been shown as follows.

(1) The thermal-mechanical coupling finite element models including the geometric and FEM models and solution conditions were applied to calculate the effective strain and temperature and extrusion force during ES extrusion. The maximum temperature rise in the billets could not increase with billet temperature rising. The temperature of rod surface increased continuously with development of ES extrusion. The evolutions of extrusion load curve and effective stress and temperature can be divided into three stages obviously. ES extrusion pressure is very sensitive to friction coefficient, so it is necessary to carry on lubrication in the process of hydrostatic extrusion. The peak extrusion force increases with extrusion speed.

(2) The ES die structures have been manufactured and installed to the horizontal extruder. ES formation was applied to fabricate AZ31 magnesium alloy rod at preheated temperature of $420^{\circ} \mathrm{C}$ with speed of $2 \mathrm{~mm} / \mathrm{s}$. The simulation results and microstructure observation showed that ES process can introduce compressive and accumulated shear strain into the magnesium alloy. The ES extrusion would cause severe plastic deformation and improve the dynamic recrystallization during ES extrusion. The microstructures show that ES is an efficient and inexpensive grain refinement method for magnesium alloys. ZenerHollomon parameters during ES process showed that the grains of magnesium would be gradually refined.

\section{Conflict of Interests}

The author declares that he is the sole author for this paper and has no direct financial relation with the commercial identities mentioned in his paper that might lead to a conflict of interests for others.

\section{Acknowledgments}

This work was supported by the National Science Foundation for Distinguished Young Scholars of China (Grant no. 51101176) and by the open fund for Key Laboratory of Manufacture and Test Techniques for Automobile Parts (Chongqing University of Technology), Ministry of Education in 2013 .

\section{References}

[1] M. Furui, H. Kitamura, H. Anada, and T. G. Langdon, "Influence of preliminary extrusion conditions on the superplastic properties of a magnesium alloy processed by ECAP," Acta Materialia, vol. 55, no. 3, pp. 1083-1091, 2007.

[2] S. X. Ding, W. T. Lee, C. P. Chang, L. W. Chang, and P. W. Kao, "Improvement of strength of magnesium alloy processed by equal channel angular extrusion," Scripta Materialia, vol. 59, no. 9, pp. 1006-1009, 2008.

[3] R. B. Figueiredo, P. R. Cetlin, and T. G. Langdon, “The processing of difficult-to-work alloys by ECAP with an emphasis on magnesium alloys," Acta Materialia, vol. 55, no. 14, pp. 47694779, 2007.

[4] D. Orlov, G. Raab, T. T. Lamark, M. Popov, and Y. Estrin, "Improvement of mechanical properties of magnesium alloy ZK60 by integrated extrusion and equal channel angular pressing," Acta Materialia, vol. 59, no. 1, pp. 375-385, 2011.

[5] L. L. Chang, Y. N. Wang, X. Zhao, and J. C. Huang, "Microstructure and mechanical properties in an AZ31 magnesium alloy sheet fabricated by asymmetric hot extrusion," Materials Science and Engineering A, vol. 496, no. 1-2, pp. 512-516, 2008.

[6] H. Hu, D. Zhang, F. Pan, and M. Yang, "Analysis of the cracks formation on surface of extruded magnesium rod based on numerical modeling and experimental verification," Acta Metallurgica Sinica, vol. 22, no. 5, pp. 353-364, 2009.

[7] A. O. Tay, M. G. Stevenson, G. de Vahl Davis, and P. L. B. Oxley, "A numerical method for calculating temperature distributions in machining, from force and shear angle measurements," International Journal of Machine Tool Design and Research, vol. 16, no. 4, pp. 335-349, 1976.

[8] J. Zhou, L. Li, J. Mo, J. Zhou, and J. Duszczyk, "Prediction of the extrusion load and exit temperature using artificial neural networks based on FEM simulation," Key Engineering Materials, vol. 424, pp. 241-248, 2010.

[9] X. Gong, H. Li, S. B. Kang, J. H. Cho, and S. Li, "Microstructure and mechanical properties of twin-roll cast $\mathrm{Mg}-4.5 \mathrm{Al}-1.0 \mathrm{Zn}$ 
sheets processed by differential speed rolling," Materials and Design, vol. 31, no. 3, pp. 1581-1587, 2010.

[10] C. I. Chang, C. J. Lee, and J. C. Huang, "Relationship between grain size and Zener-Holloman parameter during friction stir processing in AZ31 Mg alloys," Scripta Materialia, vol. 51, no. 6, pp. 509-514, 2004. 

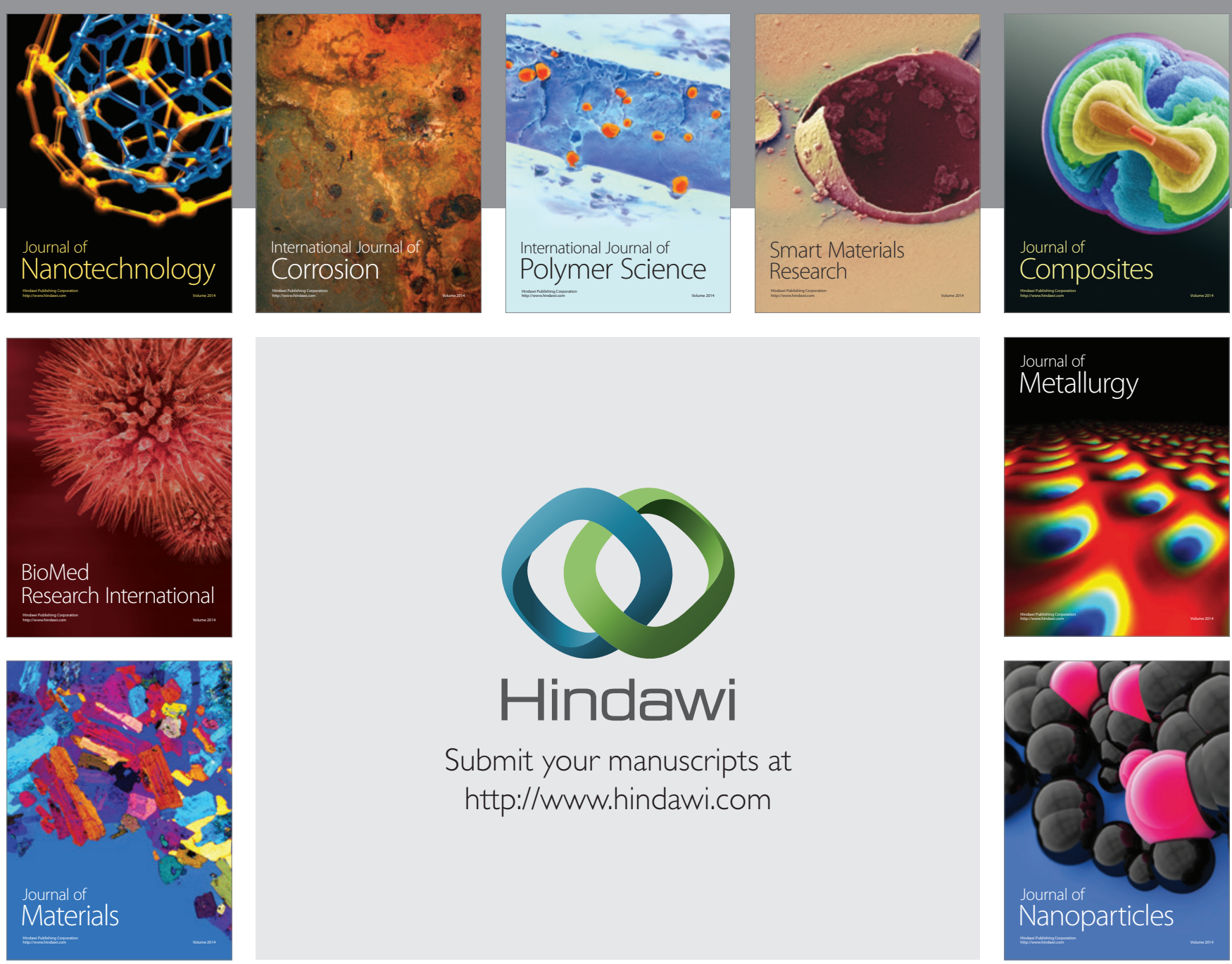

Submit your manuscripts at http://www.hindawi.com
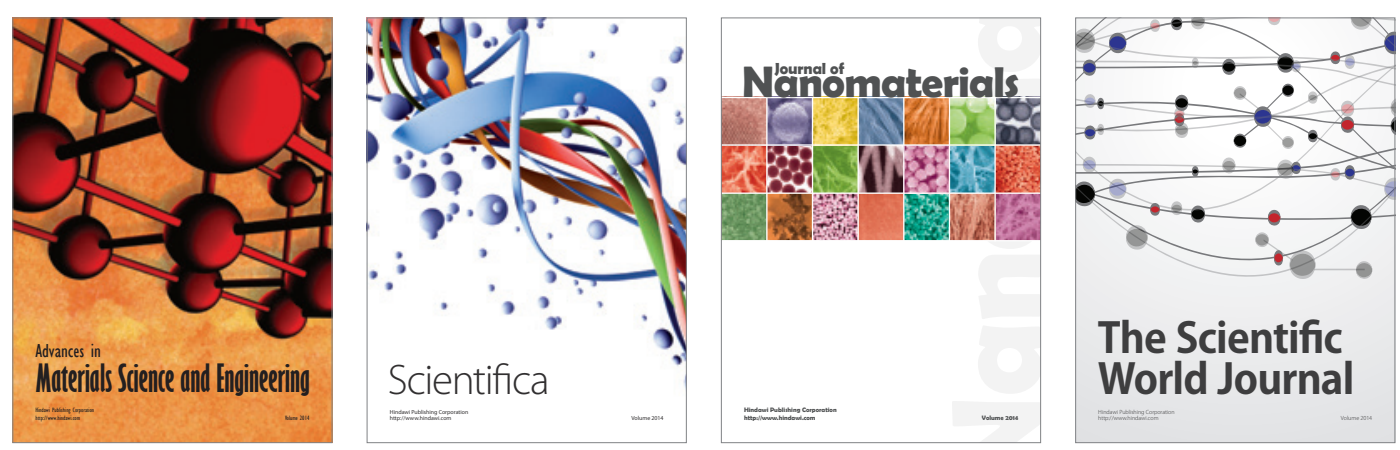

\section{The Scientific World Journal}
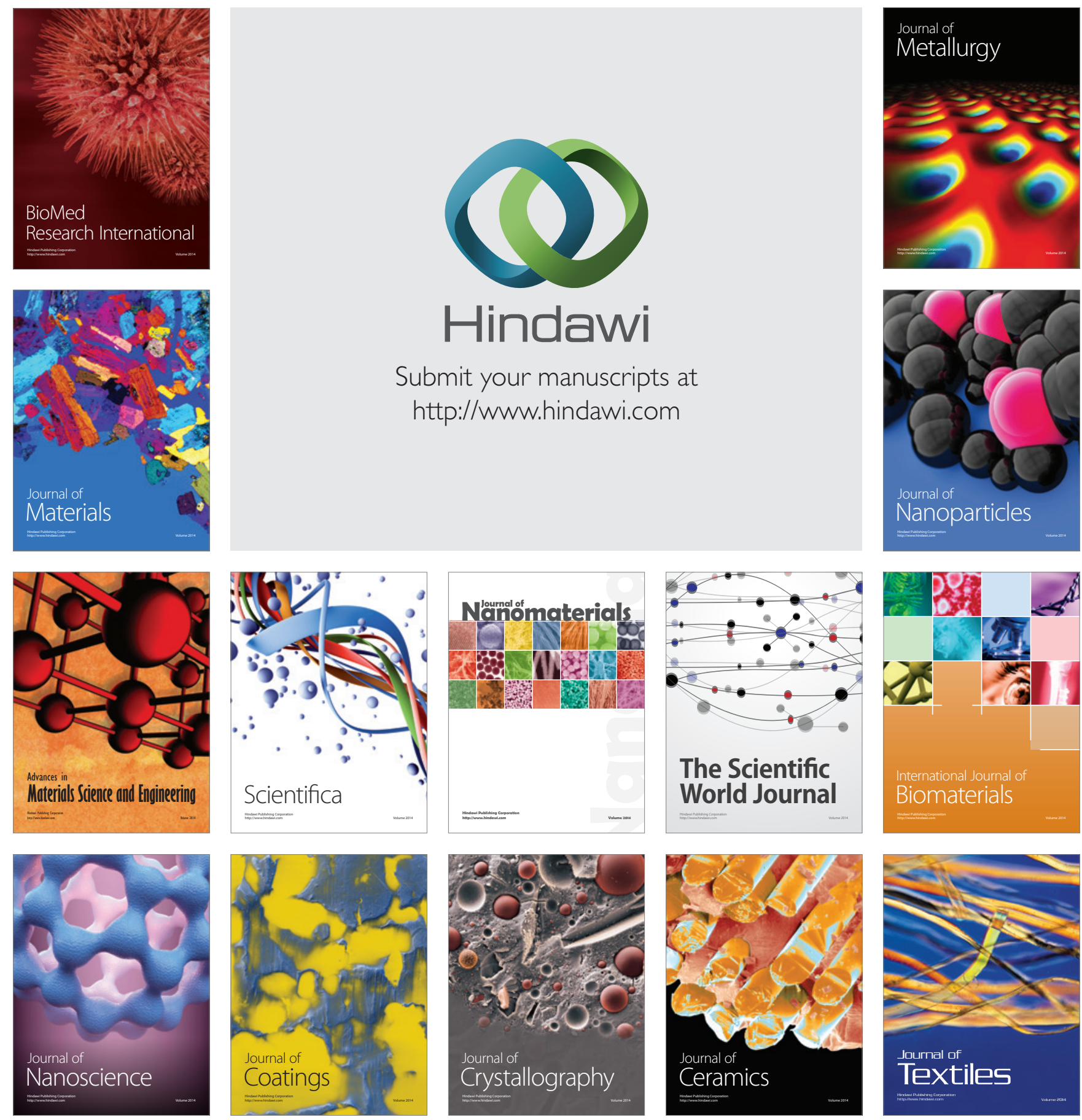